\title{
At your next conference ask where the patients are
}

\author{
Fiona Godlee editor in chief
}

The BMJ

It may not feel like it just now, but what we have is doctor centred care. Perhaps also institution, manager, and nurse centred care. What we don't yet have is patient centred care, despite this being obviously what healthcare should be. But things are slowly shifting in the right direction, and The BMJ aims to help keep up the momentum.

An editorial last week summarised where we've got to with The $B M J$ 's patient partnership strategy (doi:10.1136/bmj.i4550), and there's good progress to report. We now have patients as peer reviewers of research articles and contributing to education articles; we require authors to state how patients were involved in their research or in creating an article; and we are publishing a rich array of patients' commentaries.

These efforts mirror progress elsewhere, with patients increasingly involved in designing and implementing clinical care and research. But some parts of the healthcare ecosystem have proved more resistant to change. It's now 25 years since the International Aids Conference first included patients in its discussions, but as Larry Chu and colleagues point out (doi:10. 1136/bmj.i3883), involvement of patients in medical conferences remains the exception rather than the norm. Done well, it widens the focus of presentations, encourages more patient relevant outcomes in research, and prompts improvement in the design and delivery of care, they say. Above all, it changes the culture of a conference. Although the drive has come from patients, the medical community has much to gain.

So, what does doing it well look like, and how can organisers overcome the barriers to patient involvement? With five years' experience of running a large academic medical conference in which patients play a central part, Chu and colleagues are well placed to advise. It's not enough, though essential, to have patients on the steering and programme committees from the start, they say. Organisers need also to encourage patients to attend, comment, and speak. This means making sure that patient delegates are properly looked after and supported so they can contribute on an equal footing to other participants. This is not window dressing and must not be tokenistic. Crucially, it brings patients "closer to the conversations driving the future of healthcare."

As for The BMJ, we are proud to be the first medical journal to have earned the Patients Included stamp of approval (https:// patientsincluded.org; http://bit.ly/patient-partnership), but we know there is more to do. Our patient panel meets this week to grade our work so far and tell us what it wants us to do next.

BMJ Blogs Amy Price: The evidence informed patient (http://blogs.bmj. com/bmj/2016/09/14/amy-price-the-evidence-informed-patient); Neil Betteridge: Effective involvement of patients at medical meetings (http: //blogs.bmj.com/bmj/2016/09/14/effective-involvement-of-patientsmedical-meetings-a-case-study); Dan Smyth: Patient involvement in the European Respiratory Society Congress 2015-16 (http://blogs.bmj. com/bmj/2016/09/14/patient-involvement-in-the-european-respiratorysociety-congress)

Published by the BMJ Publishing Group Limited. For permission to use (where not already granted under a licence) please go to http://group.bmj.com/group/rights-licensing/ permissions 